\title{
School Physical Education and Physical Fitness: \\ A Study of Secondary School Students in Gaborone, Botswana 博茨瓦納的學校體育及體通能
}

\author{
Olefile MOSIDI Emmanuel 0. OWOLABI \\ Department of Physical, Health Education \& Recreation, \\ University of Botswana, BOTSWANA
}

\section{莫世薘阿華納比 \\ 非洲博茨瓦納大學體育健康及康樂學系}

\begin{abstract}
Physical Education (PE) was introduced into Botswana junior secondary schools as a curriculum subject eight years ago. Although it has the status of an optional subject, it appears to enjoy wide acceptability in many schools. One would normally expect the effects of participation in classroom physical education on students to depend on the PE curriculum's physical activity contents and how these activity contents are implemented. The study was aimed assessing the role of school PE programme in Botswana secondary schools in promoting the physical fitness levels of students. It involved 300 male Junior secondary school students in Botswana. Twenty students each were selected from 15 schools. The 20 from each school comprised 10 second and third year students offering PE as a subject and another 10 from the same years not offering PE (Non-PE). The students from each school were randomly selected from among the regular recreation participants in each school. The details and demands of the study and tests were carefully explained to the students and their PE teachers after which the school's PE teacher signed the informed consent form on behalf of the students. Data were collected on health Fitness components of body weight, BMI, Hand grip strength, flexibility, abdominal muscle endurance and cardio-respiratory endurance using established and acknowledged tests, instruments and protocols. Null hypothesis was set for each of the measured variables with the alpha level set at $\mathrm{p}<0.05$. Data were analysed for means, standard deviations and the difference between groups' means using the independent groups $t$ test. The results showed that the PE group was significantly superior to the Non-PE group in grip strength, abdominal muscle endurance and cardio-respiratory endurance. The two groups were not significantly different in age, body weight, BMI and flexibility. It was concluded that participation in school PE among urban male junior secondary school students in Botswana enhanced selected physical fitness components. This enhancement could be specifically attributed to the regular participation in the physical activities inherent in the PE subject and/or the PE students' increased and motivated participation in the schools' recreational and sporting activities.
\end{abstract}

Keywords: secondary school students, Physical Education, Physical activity, Physical Fitness.

\section{摘 要}

本文旨在探討非洲博茨瓦納學校體育和體適能，結果顯示學校體育有助提升學童的體適能，以及參與康體活動的動機。 


\section{Introduction}

School Physical Education is a curriculum subject which involves physical activities and theoretical components. Physical inactivity is a current public health concern among children and youths. There are several identified consequences of inadequate physical activity (PA) not only to adults but more specifically to the youths. A physically fit youth may be expected to graduate into a physically fit adult. Youths can only be leaders of tomorrow if they live a healthy, purposeful and productive life. In addition to general body debility, aches and pains, low productivity and absenteeism from school, one of the obvious and easily discernible indices of inadequate PA is overweight and obesity. Specifically, overweight and obesity have been linked to several adverse health problems. The risk of coronary heart disease (CHD), increases with increased adiposity. Apart from its predisposition to coronary heart diseases, Type 1, diabetes, hypertension, Pollack et al. (2007) reported a strong association between overweight and obesity and traumatic workplace injuries among manufacturing employees. While McCarthy, Jarrett, Emmett, Rogers and ALSPAC study team (2005) asserted that the prevalence of overweight and obesity has increased in pre-school children in the United Kingdom during the past decade and in several countries of the world, Hill (2006) submitted that since 1980, the entire population, both in the United State of America and throughout the world have been increasing in weight. Sorensen, Smolander, Louhevaara, Korhonen and Oja (2000) in a study on Finnish police officers found physical fitness of middle-aged police officers to be predicted strongly by physical activity in early childhood. It is thus reasonable to expect health and fitness promotion and advocacy efforts to start from early childhood. Since participation in organised school physical activities has been shown to highly correlate with children's and youths' enthusiasm for an active living in adult life, participation in organized school recreation programmes has been severally suggested to be made mandatory for all students from pre-primary to secondary school levels of education (Sigmund, Croix, Miklankova, \& Fromel, 2007). Although Parsons, Power, Logan and Summerbell (1999) submitted that parental obesity, low economic status and early maturation were some of the major factors that predispose to overweight and obesity in childhood, latter research findings indicated the increasing prevalence of overweight and obesity to be independent of socio-economic status (Corvalan et al. 2007; Fouad et al. 2006; McCarthy et al. 2005). Physical Education (PE), as a form of organized physical activities, appears viable as a vehicle for inculcating active living in children and youths. The PE curriculum however, must be health and fitness focused and the method and modes of teaching it must match these objectives.

Physical Education (PE) was introduced in Botswana schools curriculum, as a general study subject (RNCE, 1993). A general study subject is an enrichment or supplementing course and is therefore an optional subject rather than a core one. Very recently, it has been introduced under the same status in the senior secondary schools. One of the key aims of the strategies of the Revised Botswana National Policy on Education (RNPE, 1994) is to improve general education so as to prepare students more effectively for life, citizenship and the world of work. Arguably, PE is one of the few curriculum subjects that truly and legitimately enhance the achievement of the objectives of all the educational domains of cognitive, affective and psychomotor.

The traditional or general objectives of $\mathrm{PE}$ as a subject of study in schools are for neuromuscular or skill development, cognitive development, socio-affective development and physical development. However, the physical development objective appears directly related to students health. The neuromuscular or skill development objective enables students to acquire various sports skills, which in turn is expected to stimulate the love for, and participation in active recreation. It is well known that one of the major hindrances to participation in recreation is lack of relevant skills. Students are expected to recreate if they are have recreation opportunities. Recreation opportunities would include the acquisition of relevant motor skills and the presence of recreation facilities in the environment. Roux et al. (2007) reported that people living in areas with the highest density of recreation resources were more likely to report participation in physical activity, compared to people living in areas with little or no recreation resources.

Corbin (1997) argued that although all the traditional objectives of PE are important for individual and national development, the paramount objective is physical activity promotion. An active child would be expected to grow into an active adult (McFarlands \& Heelan, 2005; Coe, Pivarnic et al, 2005; ACSM, 2001; Taylor, Balir et al 1999). Trudeau, Laurencelle and Shephard (2004) in a study to examine the relationships between adult physical activity at 35 years and physical activity as a 
child reported an association between physical activity as a child and as an adult. In the same study, they also found a strong positive impact of early Physical Education upon adult physical activity. Similarly, Kraut, Melamed et al (2003) in a study of the impact of school age sports on leisure time physical activity in adults reported that organised school age sporting activities influenced future leisure time physical activity. However, Carroll, Hostetter and Eastman (1997) found no correlation between enrolment in Physical Education in high school and leisure time physical activity in a study on post-secondary school students. It would thus appear that, the outcome of any school PE curriculum would depend on whether the curriculum is health oriented or sports oriented (Gebara, Gibson \& Rosenberg, 2005; Beets \& Pitetti, 2005). It can also be argued that the method and mode of teaching the PE curriculum would influence the outcomes.

Many empirical studies have corroborated the positive impact of regular physical activities on the physical fitness and health of school students both in the present and in the future (Scott, 2005; McKenzie, Sallis, Kolody, Faucette et al., 2004; Pujol, Barnes et al., 2005; Pescatello, 1999; Schmidt et al, 1998, Wilmore et al, 2001, Trudeau et al 1999 ; Taylor et al, 1999). In a study to track physical activity from childhood to adulthood, Trudeau, Laurencelle and Shephard (2004) reported a positive impact of early required PE upon adult physical activity. Studies have further shown that participation in regular schools PE programmes significantly influenced participants' physical activity level, attitudes towards physical activity and perceptions of barriers to physical activities during adulthood (Pujol, Barnes et al, 2005; Beets \& Pitetti, 2005; Schmidt et al., 1998; Trudeau et al, 1999; Taylor et al, 1999). Shephard and Trudeau (2000) reported that Physical Education in primary school years have favourable long term impact on activity patterns, physiological parameters and smoking behaviour. Among the adults, the values of participation in physical activities in achieving improved physical fitness, health, wellness and productivity, both for the individual and the nation, are well documented (MacKnight, 2003; Lakka, Laaksonen et al, 2003; Howley, 1999; Pescatello, 1999; Wilmore et al 2001.). Goldfield et al. (2007), reported increases in physical activity to be associated with improvements in physical self-perception, in a study on 8-12 year-old overweight and obese boys and girls. The psycho-social benefit was also found to be independent of the changes in adiposity.
Beets and Pitteti (2005) in a study that compared the health-related fitness attributes of $14-19$ years old High School students participating in Physical Education and those not participating in Physical Education, reported significant differences in favour of PE students. Dale et al (1998) in a study on youths also reported that school PE programmes promoted physically active life style among participants. They found women to be more affected. Trudeau et al (1999), in a longitudinal study on school children, reported a significant influence of daily school Physical Education programme on physical activity levels, not only during the periods of schooling but also in adult life. They also found significant and positive changes in the children's attitude towards physical activities and perception of barriers to physical activity during adulthood. Cale and Almond (1997) found a strong association between curriculum PE and students engagement in physical activity. Coe, Pivarnik, Womack, Reeves, and Malina (2005), found significant impact of school PE on children's cardio respiratory fitness. One can infer that if participation in regular physical activities enhances students' physical fitness and health and school physical education encourages participation in regular activities, therefore school PE should enhance students' physical fitness and health.

The role of school PE in promoting physical activity and health among students furthermore seems crucial considering the implications of physical inactivity on health. Several studies have reported an association between physical inactivity in adulthood with various cardiometabolic diseases such as coronary heart disease, obesity, types 1 and 2 diabetes and colon cancer (Ginsberg, 2003; Cameron \& Welborn et al, 2003; Amano, Kanda, Hidetoshi \& Moritani, 2001; Pescatello, 1999; Howley, 1999; ACSM, 1999).

Boule, Bouchard and Tremblay (2005) found significant negative correlations between physical fitness and most components of metabolic syndrome. Ginsberg (2003), also reported the same result and suggests increased physical activities to address the underlying risk factors as well as a therapy to address specific lipid and non-lipid risk factors. Colberg (2001) posits that one of the most important factors contributing to the development of type 2 diabetes is inactivity. Physical activity is associated with lowered risk of all-cause mortality, as well as mortality and morbidity associated with chronic life style diseases (Lambert, Bohlmann \& Cowling 2001). 
Physical Education has been demonstrated severally, to be an efficient and effective prophylaxis in preventive and curative medicine particularly for lifestyle-related diseases and infirmities (Ketelhut, Franz, \& Scholze, 2004; ACSM, 2004). In the study to determine the longterm effect of regular exercise training as a monotherapy on both BP at rest and during exercise, Ketelhut, Franz, and Scholze presented results that demonstrated that longterm aerobic exercise is associated with a decrease in BP at rest and during exercise which is comparable to drug therapies. They further reported that the anti-hypertensive effects of regular training could be maintained for as long as three years.

Body mass index (BMI) characterictics not only signify success or failure in specific sports, they also have been shown to be very important correlates of cardio-metabolic diseases (Otte et al, 2000; Heymsfield et al., 2007; Heljastek, Pihl, Jurimae, 2001; Van-der-Sande et al 2001; Guerra et al, 2002). BMI is a simple measure of the lean weight and fat weight components (Abernethy et al, 1996) and is widely used in epidemiological studies as a determinant of health risk (Morrow (jr.), Jackson, Disch \& Mood, 1995; Van-der-Sande et al 2001). BMI is also an index of general body fat or total body fat (Fouad et al. 2006; Heitmann et al. 2004). Overweight and obesity result from positive energy balance, that is, consuming more calories of energy that one uses daily. Apart from the psychological impact of obesity on selfesteem, it has adverse health implications. In a study on second year male and female PE students and nonPE students, Philippaerts et al (1996) found the PE students to carry less body fat percent and to be more mesomorphic and less endomorphic than non-PE students. In a study to assess physical activity levels of 11-14 year old adolescent girls, Cale (1996) found inadequate physical activity and recommended PE as a compulsory curriculum subject for school children. This is more so when obese adolescents become obese adults (Freedman, Khan et al. 2005; Gordon-Larsen, Adair et al, 2004; ACSM 2001; Whitaker, Wright et al, 1997). Hence participation in school physical education programme would be expected to improve the weight and body composition of students.

In a study on 8 - 15 years old Portuguese school children, to evaluate the relationship between cardiorespiratory (CR) fitness, body composition and blood pressure, Guerra et al (2002) found that age and body weight explained significantly the amount of systolic blood pressure (BP) and diastolic BP. Heljaste, Pihl and Jurimae (2001) reported that physical inactivity and over weight had significant relationships with musculoskeletal disorders in males and general health disorders in females in a study of former top level swimmers.

JAMA (1996) in their position statement on physical activity and cardiovascular health submitted that physical, activity plays a significant role in enhancing cardiovascular health. They recommended that all Americans should engage in regular physical activity. Scott (2005) also recommends regular Physical activities in combating depression.

Character education and discipline acquired through school PE programme have also been shown to be carried into adult life. For example, Trudeau et al (1999) found lower prevalence of regular smokers in experimental men than in controls in a longitudinal study on relationship between exposure to school PE and adult life.

Metabolic syndrome and the consequent coronary heart disease (CHD) are on the increase world-wide in both developing and developed countries (Fontana, Villareal, Weiss, Racette, Steger-May, Klein et al. 2007; Bovet, Chiolero, Madeleine, Gabriel \& Stettler, 2006). The unwholesome lifestyle and poor physical fitness levels of Botswana students have been empirically corroborated (Owolabi \& Kalui, 1997; Molamu, 1990; Setshwane, 1994). For instance, many observations and reports have been made on the low work output and productivity of Batswana workers (Lloyds, 1999; Owolabi \& Shaibu 1999; Botswana Ministry of Health, 1996). Indeed studies conducted on Botswana youths reported lower levels of physical fitness, when compared with their counterparts in other countries Corlett, 1984a, 1984b; Owolabi, unpublished data). Many research studies on youths and social problems in Botswana (Intersectoral Committee on Family Life Education, 1989; Setshwane, 1994; Molamu, 1990) implicated the absence of recreational opportunities as a major contributory factor. Lack of recreational opportunities would include lack of recreational facilities and recreational skills. More recently, HIV/AIDS has been nationally recognised as the greatest challenge Botswana has faced (Botswana National Aids Coordinating Agency (NACA, 2003). Indeed, in many sectors of Botswana, the impact of HIV/AIDS is substantial and has resulted in tremendous increase in cost. For example, according to Phumaphi, the then Botswana Minister of 
Health, up to October 2002, 60 percent of all medical wards admissions were due to HIV/AIDS - related conditions, with some of the wards running at 95 percent occupancy rates due to HIV/AIDS (Botswana NACA, 2002).

Thus, exposure to PE curriculum in school is expected to socialise children and youths, not only into physical activities and sports but also into a healthy and active life style. Enrolment in a regular PE programme as a subject of study is expected to make the participants physically educated persons and as such make them value and participate in physical activity both now and through adult life. This should be beneficial to the individual and the nation as it would drastically reduce the costs on health and relieve the heavy burden on health facilities. However, these expected outcomes would depend on the focus of the curriculum contents and the mode of its implementation. This is because a curriculum would only achieve what the contents state, particularly with respect to physical fitness, competitive sports, sensitisation on the need for recreation and other pertinent PE objectives. The implementation of these contents and the knowledge and competency of the implementers are also very crucial in achieving the desired curriculum outcomes. McKenzie et al. (1997) submitted that specialists in Physical Education produced best outcomes from curriculum PE programmes than non-trained peers.

The school Physical Education curriculum of the community junior secondary schools in Botswana comprises several courses, which range in physical activity intensity from near-zero to vigorous. About 70 percent of the PE curriculum involves structured physical activity. Furthermore, the mode of teaching the course largely depends on the teacher although all activity based topics including those on sports are expected to be taught on the sports fields. Up till this time, the PE final examination is only examined as theory papers.

This study was aimed assessing the role of school PE programme in Botswana secondary schools in promoting the physical fitness levels of students. This was done by comparing the physical fitness levels of Community Junior Secondary students who were offering $\mathrm{PE}$ as a curriculum subject, as well as regularly participating in the schools' evening recreation programme and those who were not offering it and were only regularly participating in the schools' recreation programme. The study is expected to add to the pool of knowledge on effects of secondary school PE on participants' physical fitness. One of the main attractions to Botswana Government before agreeing to the teaching of PE as a subject in Botswana secondary schools was to improve the physical fitness of youths so as to enhance the productivity of tomorrow's Botswana's adults. The study would also reveal the impact of the school PE subject on health-related fitness of students. The findings may also be used to justify the need for compulsory school PE in secondary schools in Botswana rather than being an optional subject. A physically educated child is expected to appreciate and participate in regular physical activities during recreation, both now and in the future. A physically educated person is expected to possess high self-efficacy in recreational activities and pursue a healthy and active life style.

\section{Methods}

The quasi-experimental research design was adopted. The quasi treatment is enrolment and participation in school evening recreation programme and PE classes while the control/reference group were students of same level of studies who were not enrolled in the school PE subject but regularly participate in the school's recreation programme. No attempt was made to control the regular lifestyles of both groups of subjects. However, none of the subjects was involved in regular training and competition as none was in any competitive team during the time of study whether for the school or for community clubs. In a preliminary survey of over 1000 secondary school students schooling in and around Gaborone, on why the students chose physical education as a subject, over 90 percent of the students chose the subject in order to control weight, to keep fit and to further their interest in sports. Less than 15 percent of the students actually chose PE in order to further their interest in sport. There were also cases where the school authorities made it mandatory for all their students to offer PE. These happened where the school management strongly believed in the health promoting values of $\mathrm{PE}$ and/or where the school was very interested in competitive sports and wanted to use PE to enhance its sports base. 
The subjects for the study were 300 male junior secondary school students in Gaborone (the capital of the country), Botswana. Twenty students each were selected from 20 community junior secondary schools. The 15 from each school comprised 10 second and third year students offering $\mathrm{PE}$ as a subject and another 10 from the same years not offering PE (Non-PE). Both groups of subjects were regularly involved in schools' evening recreational programmes. The students from each school were randomly selected from among the regular participants in schools' evening recreation programmes. The details and demands of the study and tests were carefully explained to the students and their PE teachers after which the school's PE teacher signed the informed consent form on behalf of the students.

Data were collected on health Fitness components of body weight, BMI, Hand grip strength, flexibility, abdominal muscle endurance and cardio-respiratory endurance using established and acknowledged instruments and protocols. The data collection process was spread over two days and the tests were so arranged that no test would influence the performance of the following one. In addition, adequate recovery period was allowed between trials and tests.

\section{Order of Testing}

Day 1

Day 2

Age

Grip Strength

TestResting Heart rate Trunk flexibility Test

Body weight Cardio-Respiratory Endurance

Test

Height

Skinfold Measurements

Muscle Endurances Test

Data were gathered with standard equipment using standardised protocols. The two researchers standardised their procedures to ensure high objectivity. The researchers and trained assistants took measurements for specific variables for all subjects.
Body Mass Index was used to estimate level of overweight and obesity. The handgrip dynamometer was used to measure subjects' grip strength of the dominant arm in kilograms and to the nearest $0.1 \mathrm{~kg}$. The standard protocol was followed. Two trials were given, with five minutes recovery between trials and the better was recorded.

Sit and Reach trunk flexion test was used to measure flexibility. Following three initial warm-up trials, subjects were give three trials and the mean was recorded to the nearest $0.1 \mathrm{~cm}$. According to Martin, Jackson, Morrow and Liemohn (1998), the development and maintenance of low back and hamstring flexibility is recognised as important components of physical fitness. The sit and reach test measures lumbo-sacral and gleno-humeral joints' flexibility.

Abdominal Muscle endurance was measured with 60 -sec repeated sit-up test. The standard protocol was followed. Two trials were given with ten minutes recovery between trials. The better of the trials was recorded in repetitions.

The subject's cardio-respiratory endurance was measured with the resting heart rate (RHR) and the 12 minutes run. To obtain the subject's RHR, they were given 20 minutes compulsory sitting on a chair after reporting in the test site. Then their RHR was taken by the researchers. The Stethoscope was used to obtain HR values from the hollow of the neck (carotid artery). It was taken for 15 seconds and multiplied by four to obtain the minute heart rate value. Two measurements were taken over the two test days and the average was recorded. The test-retest reliability of the RHR using intra-class correlation procedure $(\mathrm{R})$ had a coefficient of $\mathrm{R}=0.95$. For the 12 minutes run, subjects ran around a 400 metre athletic track of the university of Botswana stadium attempting to cover as much as possible distance in 12 minutes. The 400 metre track was divided into five 80 metre distances. The distance covered in 12 minutes was recorded to the nearest metre. All subjects were continuously motivated with words of encouragement throughout the tests.

Null hypothesis was set for each of the measured variables with the alpha level set at $\mathrm{p}<0.05$. Data were analysed for means, standard deviations and the difference between group's means was tested with the independent groups' 't test' 


\section{Results}

The results are presented on Table 1.

Table 1. Physical Fitness characteristics of Junior Secondary School male PE-students and Non-PE Students $(\mathrm{N}=400$; Means \pm Standard Deviation $)$.

\begin{tabular}{|c|c|c|c|}
\hline Variable & PE Students & NON PE Students & t-Test* \\
\hline Age (yrs) & $14.80 \pm 2.06$ & $14.63 \pm 2.06$ & 0.62 \\
\hline Height (m) & $1.598 \pm 0.14$ & $1.567 \pm 0.12$ & 0.07 \\
\hline Body weight $(\mathrm{kg})$ & $51.00 \pm 12.40$ & $47.30 \pm 14.26$ & 1.86 \\
\hline Body Mass Index $\left(\mathrm{Kg} / \mathrm{m}^{2}\right)$ & $19.69 \pm 5.16$ & $19.09 \pm 5.06$ & 0.86 \\
\hline Grip Strength (Kg) & $30.98 \pm 9.50$ & $26.73 \pm 8.70$ & $3.59 *$ \\
\hline Trunk Flexibility (cm) & $29.83 \pm 12.16$ & $32.78 \pm 11.86$ & -1.90 \\
\hline $\begin{array}{l}\text { Abdominal Muscle Endurance } \\
\text { (reps) }\end{array}$ & $24.70 \pm 15.80$ & $19.60 \pm 9.00$ & $3.06^{*}$ \\
\hline Rest Heart Rate & $72.34 \pm 9.62$ & $73.20 \pm 12.44$ & -0.67 \\
\hline $\begin{array}{l}\text { Cardio-Respiratory Endurance } \\
(\mathrm{km})\end{array}$ & $4.40 \pm 1.05$ & $3.40 \pm 0.58$ & $4.79 *$ \\
\hline
\end{tabular}

$* \mathrm{p}<0.05$.

In the physical characteristics of age, height, body weight and BMI there were no significant differences between the PE and Non-PE groups. However, the PE group had $7.8 \%$ higher body weight than the Non-PE group. The BMI values of both groups are just below the desirable BMI value (i.e. BMI of $20-25 \mathrm{~kg} / \mathrm{m}^{2}$ ) (Clinical Guidelines on identification, evaluation and treatment of overweight and obesity in Adults 1998). Even using the paediatric definition for 15 year-old males (Cole, Bellizzi, Flegal \& Dietz, 2000) which is $23.3 \mathrm{Kg} / \mathrm{m}^{2}$ for overweight and $28.3 \mathrm{Kg} / \mathrm{m}^{2}$ for obesity, the samples on the average fall below either cut-off point.

On motor performance measures the two groups significantly differed in grip strength, muscle endurance of the abdomen and in cardio-respiratory endurance, with the PE group recording the higher and better values in all. They did not significantly differ in trunk flexibility.

\section{Discussion}

The fact that the two groups did not significantly differ in age and height may not be unexpected as the variables are not expected to be changed by participation in organised physical activities. However, the seven percent difference in body weight indicates a tendency for PE students to have higher body weight than NonPE students.. The higher body weight among the PE group may be related to the development of muscle mass among the PE group consequent to participation in curriculum PE. Generally, curriculum PE has been shown to be effective in improving muscle strength of participants. This finding agrees with that of Beets and Pitteti (2005) which in a study that compared the healthrelated fitness attributes of 14 - 19 years old High School students participating in Physical Education and those not participating in Physical Education, reported 
significant differences in favour of PE students. It agrees with Pujol et al (2005) who following three weeks Physical Education class, found significant changes in predicted $\mathrm{VO}_{2}$ max, abdominal muscle endurance and muscle strength. Although the PE group had a slightly higher but non-significant BMI than the Non-PE group, both groups fall within the 'desirable BMI' classification of Sharkey (1997) which is $19-25 \mathrm{Kg} / \mathrm{m}^{2}$ and other researchers (Aronne, 2002; Deckers, Podolsky, Treiber, Barbeau, Gutin and Snieder 2004).

The 10 percent higher though non-significant trunk flexibility in the Non-PE group is hard to explain. It may be due to the fact that the PE programme, which the PE group undertook was not much trunk flexibility demanding to effect significant adaptation in this area. It might mean that the recreation activities regularly embarked upon by the non-PE group place more stress on trunk flexibility than those of the PE group. However, it is well known that trunk flexibility is of universal importance in human movement of any type. Indeed, in a study on national physical education curriculum, motor and cardiovascular health-related fitness in Greek children, Koutedakis and Bouziotas (2003) concluded that the Greek national PE curriculum for secondary schools did not achieve the required levels of motor and cardiovascular health related fitness and should be re-considered. Of course, it is the content of the PE curriculum that would determine the physical and motor fitness impacts on participants. The mode of delivery of the PE curriculum may also be expected to influence the outcomes on the students.

The non-significant difference in resting heart rate is not surprising, as resting heart rate seems to have little or no physiological value as an indicator of physical fitness. This might be so because resting heart rate is easily influenced by extraneous and environmental factors such as temperature, mood, anxiety, prior activities and state of excitement of the subjects. This also agrees with the findings of Wilmore et al (2001) in a study of 607 previously sedentary men and women following 20 weeks of endurance training. Although they reported significant decreases in exercise heart rate and diastolic blood pressure, they found no difference in resting heart rate.
The significantly higher and better abdominal muscle endurance and cardio-respiratory endurance of the PE group indicate that the PE curriculum of the Junior secondary school was active enough to elicit adaptations in these physical fitness attributes. These findings however, contradict those of Koutedakis and Bouziotas (2003), which reported an inferior motor and cardiovascular health - related fitness profile in the PE group compared to the PE-plus group. When Farley, Caputo and Tseh (2004) found no impact of school-based Physical Education on the percent body fat of their subjects, they concluded that, in addition to increased frequency of students' exposure to $\mathrm{PE}$, the content of the PE curriculum must be regularly assured for its health-related fitness predispositions. Beets and Pitetti (2005) also found PE-only group to exhibit the lowest levels of muscle endurance and cardiovascular fitness in comparison to youth participating in combined $\mathrm{PE}$ and school-sponsored sports.

The finding of a positive influence of enrolment in PE programme on some physical fitness parameters, particularly with Cardio-respiratory endurance, agree with the established impact of regular physical activities on physical fitness (McKenzie, Derby, Webber, Luepker \& Cribb, 2002; Sallis, McKenzie, Alcaraz, Kolody, Faucette \& Hovell, 1997; Coe, et al, 2005; Fairclough \& Stratton, 2005, Trudeau et al 2004, Pujol et al, 2005). Although Pujol et al (2005) found no significant change in BMI and maximum push-up following three weeks Physical Education class, significant changes were recorded in predicted $\mathrm{VO}_{2}$ max, abdominal muscle endurance and muscle strength.

\section{Conclusion}

Based on the outcome of this study, and on the fact that many physiologists and researchers on physical fitness equate cardiovascular fitness with physical fitness (JAMA, 1996; American College of Sports Medicine (ACSM) 2004; Coe, Pivarnik, Womack, Reeves, \& Malina, 2005), it was concluded that regular school PE programme enhances, the physical fitness level of Botswana secondary school students. It is hoped that this enhanced fitness will in turn enhance their health, wellness and productivity. The habitual participation in physical activities and its benefits are further expected to be carried into adult life. 
It was recommended that $\mathrm{PE}$ be made a compulsory subject in all Botswana schools as a way of enhancing students' fitness and productivity both now and presumably, in their future adult life.

\section{References}

Abernethy, P., Olds, T., Eden, B., Neill, M., \& Baines, L. (1996). Anthropometry, Health and Body Composition. In Norton, K, \& Olds, T. (Eds.), Anthropometrica. Sydney: University of New South Wales Press.

Amano M, Kanda T., Hidetoshi U. \& Moritani T. (2001). Exercise training and autonomic nervous system activity in obese individuals. Medicine and Science in Sports and Exercise, 33(8), 1287 -1291.

American College of Sports Medicine (1999). Current Comment: Women's heart health and a physically active lifestyle. http://www.msse.org

American College of Sports Medicine (2001). New Release: Obesity riskier than lack of physical activity for Coronary Heart Disease in adolescents. Medicine and Science in Sports and Exercise, 33(2), 270.

American College of Sports Medicine (2001). Position Stand: Exercise and Type 2 diabetes. http://www. msse.org

American College of Sports Medicine (2004). Position Stand: Exercise and Hypertension. Medicine and Science in Sports and Exercise, 36(3), 533 - 553.

Aronne, L. J. (2002). Classification of obesity and assessment of obesity-related health risks. Obesity Research 10, 105S - 115S.

Beets M., \& Pitetti K. (2005). Contribution of Physical education and sport to health-related fitness in high school students. Journal of School Health, 75 (1)25 30.

Botswana Ministry of Health, Botswana (1996): Seminar: Health and Manpower Planning, NDP 8- 1997-2002. Gaborone: Ministry of Health.
Botswana National Aids Coordinating Agency (2002). Botswana 2002 second generation HIV/AIDS surveillance. A Technical Report. Gaborone:NACA/ AIDS/STD.

Botswana National Aids Coordinating Agency (2003). Botswana 2003 second generation HIV/AIDS surveillance. A Technical Report. Gaborone:NACA/ AIDS/STD.

Boule, N.,G., Bouchard, C. \& Tremblay, A (2005). Physical fitness and the metabolic syndrome in adults from the Quebec Family Study. Canadian Journal of Applied Physiology, 30(2), 140.

Bovet, P., Chiolero, A., Madeleine, G., Gabriel, A. \& Stettler, N. (2006). Marked increase in the prevalence of obesity in children of Seychelles, a rapidly developing country, between 1998 and 2004. International Journal of Pedatric Obesity, 1(2), 120128 ,

Cale, L. (1996). An assessment of the physical activity level of adolescent girls - implication for physical education. European journal of Physical education (England), 1(1) $46-55$.

Cale L., \& Almond, L. (1997). The physical activity level of English Adolescent boys. European journal of Physical Education (West Malling, England), 2(1), 7482.

Cameron, A., Welbom, T., Drustan, D., Owen, N., Salmon, J., Dalton, M., Jolley, D., \& Shaw, J. (2003). Overweight and obesity in Australia: the 1999 - 2000 Australian Diabetes, obesity and lifestyle study (AusDiab). Med. J. Aust, 178(9), 427 - 432.

Carroll C., Hostetter R., \& Eastman W. (1997). High school Physical education course enrollment \& leisure time physical activity of post secondary school students. Avante (Gloucester, Ont), 3(1), 61-70.

Clinical Guidelines on identification, evaluation and treatment of overweight and obesity in Adults. The evidence Report, National Institute of Health (1998). Obesity Research, 6 (Suppl), 51S - 209S. 
Coe, D., Pivarnic, J. Womack, C., Reeves, M., \& Malina, R. (2005). Role of Physical Education on cardiorespiratory Fitness in middle school children:120 Board \#27 9:30 AM - 11:00 AM. Medicine and Science in Sports and Exercise, 37(5), Suppl. S17.

Colberg, S. (2001). Exercise: A diabetes "cure" for many. ACSM's Health and fitness Journal, 5(2), 20-26.

Cole, T., Bellizzi, M., Flegal, K., \& Dietz, W. (2000). Establishing a standard definition for child overweight and obesity worldwide: international survey. BMJ, 320, $1240-3$

Corbin, C. B., (1997). The future of Physical education: Physical activity promotion is the key. Journal of inter-disciplinary research in physical education, 2(2), $1-10$

Corlett, J. (1984a). A power function analysis of physical performance by Botswana children. Journal of Sports Science, 2(2), 131-137.

Corlett, J. (1984b) Health-related fitness of young Batswana adults. In Botswana Notes and Records. The Journal of Botswana Society, 16, 59-61.

Corvalan, C., Gregory, C., Ramirez-Zea, M., Martorell, R., \& Stein, A. (2007). Size at birth, infant, early and later childhood growth and adult body composition: a prospective study in a stunted population. International Journal of Epidemiology, doi:10.1093/ije/dym010

Dale D., Corbin C., \& Cuddily, T. (1998). Can conceptual physical education promote physically active life style? Paediatric Exercise Science 10, (2), 97-109.

Deckers, J., Podolsky, R., Treiber, F., Barbeau, P., Gutin, B., \& Snieder, H. (2004). Development of general and central obesity from childhood into early adulthood in African American and European American males and females with a family history of cardiovascular disease. American Journal of Clinical Nutrition, 79(4), $661-668$
Fairclough, S., \& Stratton, G. (2005). 'Physical Education makes you fit and healthy.' Physical Education's contribution to young people's physical activity levels. Health Education Research, 20(1), 14-23.

Farley, R., Caputo, J., \& Tseh, W. (2004). The impact of school-based Physical Education on physical activity levels and percent body fat. Medicine and science in Sports and Exercise, 36(5) Suppl. S101.

Fontana, L., Villareal, D., Weiss, E., Racette, S., StegerMay, K., \& Klein, S., et al. (2007). Calorie restriction or exercises: Effects on coronary heart disease risk factors. A randomised controlled trial. American Journal of Physiology, Endocrinology and Metabolism, 293, E197-E202.

Fouad, M., Rastam, S., Ward, K., \& Maziak, W. (2006). Prevalence of obesity and its associayted factors in Aleppo-Syria. Prevention and Control, 2(2) 85-94.

Freedman D., Khan L., Serdula M., Dietz W., Srinivasan S., \& Berenson G. (2005). The relation of childhood BMI to adult Adiposity. The Bogalusa Heart Study. Pediatrics 115, (1), 22 - 27.

Gebara, D, Gibson, A., \& Rosenberg, D. (2005). Effects of Sports related and Health-related Physical Education curricula on the fitness levels of $8^{\text {th }}$ graders: 137 Board \# 11:00 am - 12:30 pm. Medicine and Science in Sports \& Exercise, 37(5) supplement: S21.

Ginsberg H (2003). Treatment for patients with the metabolic syndrome. The American Journal of Cardiology, 91(2), Suppl. 1, 29-39.

Goldfield, G., Mallory, R., Parker, T., Cunningham, T., Legg, C., \& Lumb, A. et al. (2007). Effects of modifying physical activity and sedentary behaviour on psycho-social adjustment in overweight/obese children. Journal of Pediatric Psychology, 32(7), 783-793.

Gordon-Larsen P., Adair L., Nelson M., \& Popkin B., (2004): Five year obesity incidence in the transition period between adolescence and adulthood: The national longitudinal study of adolescent health. American Journal of Clinical Nutrition, 80(3), 569 -575. 
Guerra, S., Ribeiro, J., Costa, R., Duarte, J., \& Mota, J. (2002). Relationship between Cardiorespiratory fitness, body composition and blood pressure in school children. Journal of Sports Medicine and Physical Fitness (Torino), 42(2), $207-213$.

Heitmann, B. L., Frederiksen, P., \& Lissner, L. (2004). Hip circumference and cardiovascular morbidity and mortality in men and women. Obeisty Research 12, 482-487.

Heljaste, K., Pihl, E., \& Jurimae, T (2001). Anthropometric data and physical activity of former top-level swimmers. Eesti-antropomeetriaregistri.-AastaraamatTartu 92001, 21-27.

Heymsfield, S., Gallagher, D., Mayer, L., Beetsch, J., \& Pietrobelli, A. (2007). Scaling of human body composition to stature: new insights into body mass index. American Journal of Clinical Nutrition, 86(1), $82-91$.

Howley, E. (1999). You asked for it. ACSM's Health and Fitness Journal, 3(4), 12-13.

Intersectorial Committee on Family Life Education. (1989). Profile of Youths in Botswana. Gaborone: Government of Botswana.

JAMA. (1996). Physical activity and cardiovascular health. NHI consensus development Panel on Physical activity and cardiovascular health. JAMA 276, 241.

Ketelhut, R.; Franz, I., \& Scholze, J. (2004). Regular exercise as an effective approach in antihypertensive therapy. Medicine and Science in Sports and Exercise, 36(1), 4-8.

Koutedakis, Y., \& Bouziotas, C. (2003). National Physical Education curriculum: motor and cardiovascular health related fitness in Greek adolescents. British Journal of Sports Medicine, 37, 311 - 314.

Kraut, A., Melamed, D., \& Froom, P. (2003). Effect of school age sports on leisure time physical activity in adults: The CORDIS study. Medicine and Science in Sports and Exercise, 35(12), 2038 -2042.
Lakka T., Laaksonen D., Lakka H.M, Mannikko N., Niskanen L., Rauramaa R., \& Salonen J., (2003). Sedentary lifestyle, poor Cardio-Respiratory fitness and the metabolic syndrome. Medicine and Science in Sports \& Exercise, 35(8). 1279 - 1286.

Lambert E.V., Bohlmann M.T., \& Cowling K., (2001). Physical activity for Health: understanding the epidemiological evidence for risk benefit. International - Sportmed-Journal, 1(5), 20 -25.

Lloyd, R. (1999). Productivity week. Productivity and Quality forum, 4(3), 1.

Macknight J. (2003). Exercise considerations in hypertension, obesity and dyslipidemia. Clinics in Sport Medicine, 22(1), $101-121$.

Martin, S.B., Jackson, A.W., Morrow, J., \& Liemohn, W. (1998). The rationale for sit and reach test revisited. Journal for measurement in physical education and exercise science, 2(2), 85-92.

McCarthy, H., Jarrett, K. Emmett, P., \& Rogers, I., (2005). Trends in waist circumference in young British children: a comparative study. International Journal of Obesity, 29, 157-162.

McFarland, S., \& Heelan, K. (2005). Physical Education versus lifestyle physical activity in elementary school children: 2244 Board \#33 9:00 AM - 10:30 AM. Medicine and Science in Sports and Exercise, 37(5), Suppl. S432.

McKenzie, T., Derby, L., Webber, L., Luepker, L., \& Cribb, P. (2002). Sustainability of a Health-related physical education intervention in 76 elementary schools: CATCH. Medicine and Science in Sports and Exercise, 34(5), Suppl $1 \mathrm{p}$ S301.

Mckenzie T., Sallis J., Kolody B., \& Faucelfe, F. (1997). Long term effects of a Physical Education curriculum and staff development program: SPARK. Research Quarterly for Exercise and Sports, 68(4), 280 - 291.

McKenzie, T., Sallis, J., Kolody, B., \& Faucette, F. (2004). Evaluation of a 2-year middle school Physical Education intervention: M-SPAN. Medicine and Science in Sports and Exercise, 36(8), 1382 - 1388. 
Molamu, L. (1990). Alcohol use and abuse in Botswana. A community study. NAD-publication, 18, 93 - 111.

Morrow Jr, J., Jackson, A., Disch, J., \& Mood, D. (1995). Measurement for Evaluation in Human Performance. Champaign, IL: Human Kinetics.

Otte, A., Hassler, J., Brogowski, J., Bowen, J., \& Mayhew, J. (2000). Relationship between body mass index and predicted \% fat in college men and women. Missouri-journal of health, physical education, recreation, and dance St. Louis, MI. 102000, 23-29.

Owolabi, E.O., \& Kalui, B. (1997). Teaching Physical Education in Botswana. In Marope, M \& Chapman, D (Eds.), Research in Education: Teaching and Teacher education in Botswana. Gaborone: Lentswe la Lesedi Ltd.

Owolabi, E. O., \& Shaibu, S. (1999). Country Profile: Botswana, an African success story. Health Promotion: Global Perspectives (Washington, DC), 2(3), 6.

Parsons, I. J., Power, C. Logan, S., \& Summerbell, T. (1999). Childhood predictors of adult obesity: a systematic review. Int. J. Obes. Relat. Metabolic disorder 23, 1107.

Pescatello, L. S. (1999). Exercise prescription and management for cardiometabolic health. ACSM's Health and fitness journal, 3(2), 15-21.

Phillipaerts, R.M., Claessens, A. L., Ten-brink, J.M, Vandeer-sheer, D.E., \& Leafer, B. (1996). Nutritional habits in body composition, somatotype, physical activity and cardio-respiratory fitness in male and female physical Education students. Acta Kinesiologiae Universities, Tartuensis 1, 5-22.

Pollack, K., Sorock, G., Slade, M., Cantley, L., Sircar, K., \& Taiwo, O. et al. (2007). Association between BMI and acute traumatic workplace injury, in hourly manufacturing employees. American Journal of Epidemiology. Doi:10.1093/aje/kwm058
Pujol, T., Barnes, J., \& Unterreiner, T. (2005). Fitness changes in high school females as a result of a three week Physical education class: 2233 Board \#22 10:30 A.M. - 12:00 P.M. Medicine and Science in Sports and Exercise, 37(5) Suppl. S429 -S430.

Republic of Botswana. (1993). Report of the National commission on Education 1993. Gaborone: Government printers.

Republic of Botswana. (1994). The revised National Policy on Education. April 1994. Government paper No. 2 of 1994. Gaborone: Government printers.

Roux, A., Evenson, K., McGinn, A., Brown, D., Moore, L.\& Brines, S. (2007). Availability of Recreational Resources and Physical Activity in Adults. American Journal of Public Health, 97(3), 493-499.

Sallis, J., McKenzie, T., Alcaraz, J., Kolody, B., Faucette, N., \& Hovell, M. (1997). The effects of a 2-year physical education program (SPARK) on physical activity and fitness in elementary school students. Sports, Play and Active Recreation for kids. American Journal of Public Health, 87(8), 1328 1334.

Schmidt, G. J, Walkinski, J.J., \& Stensel, D.J. (1998). The Singapore youth coronary risk and physical activity study. Medicine and Science in Sports \& Exercise, 30(1), 105 - 113.

Scott, S. (2005). Medical Report: combating depression with exercise. ACSM's Health and Fitness Journal, 9(4), 31-33.

Setshwane, M. (1994). Correlates of teenage pregnancy in Botswana. Bachelor of Arts (Social Sciences) Research Project. Gaborone: University of Botswana.

Sharkey, B.J. (1997). Fitness \& Health. Champaign IL: Human kinetics.

Shephard, R., \& Trudeau, F. (2000). The legacy of Physical Education. Influence on adult lifestyle. Paediatric Exercise Science, 12(11), 34 -50. 
Sigmund, E., Croix, M., Miklankova, L., \& Fromel, K. (2007). Physical activity patterns of kindergarten children in comparison to teenagers and young adults. The European Journal of Public Health, doi:10.1093/25/04/2007

Sorensen, L., Smolander, J., Louhevaara, V., Korhonen, O., \& Oja, P. (2000). Physical activity, fitness and body composition of Finnish police officers: a 15-year follow-up study. Occup Med, 50(1), 3-10.

Taylor, W.C., Blair, S.N., Cunnings, S.S., Wur, C. C., \& Malina, R. M. (1999). Childhood and Adolescent physical activity patterns and adult physical activity. Medicine and Science in Sport and Exercise, 31(1), $118-123$.

Trudeau, F., Laurencelle, L., \& Shepherd, R. (2004). Tracking of physical activity from childhood to adulthood. Medicine and Science in Sports and Exercise, 36(11), 1937 - 1943.

Trudeau F., Laurencelle, L., Trembley, J., Rajic, M., \& Shepherd, R. (1999). Daily primary school physical education: Effects on physical activity during adult life. Medicine and Science in Sports and Exercise, 31(1), 111-117.
Van-der-Sande, M. A. B., Ceesay, S. M., Milligan, P. J. M., Nyan, O. A., Banya, W. A. S., Prentice, A., McAdam, K. P. W., \& Walraven, G. E. L. (2001). Obesity and undernutrition and cardiovascular risk factors in rural and urban Gambian communities. American-Journal of Public Health Washington,-D.C. 91(10), 1641-1644.

Whitaker, R., Wright, J., Pepe, M., Seidel, K., \& Dietz, W. (1997). Predicting obesity in young adulthood from childhood and parental obesity. The New England Journal of Medicine, 337(13), 869-873.

Wilmore, J., Stanforth, P., Gagnon, J., Rice, T., Mandel, S., Leon, A., Rao, D., Skinner, J., \& Bouchard, C. (2001). Heart rate and Blood pressure change with endurance training: The HERITAGE family study. Medicine and Science in Sport and Exercise, 33(1), 107 -116.

\section{Correspondence:}

Prof. Emmanuel O. Owolabi

University of Botswana,

Private Bag 0022,

Gaborone, Botswana.

e-mail: owolabie@mopipi.ub.bw

Telephone: +267-3975723; Fax: +267 3185096 